\title{
Accelerated atherosclerosis after renal transplantation: an unsuspected cause of uncontrolled hypertension
}

This article was published in the following Dove Press journal: International Journal of Nephrology and Renovascular Disease 16 July 2014

Number of times this article has been viewed

\author{
Ana Pinho',2 \\ Susana Sampaio \\ Manuel Pestana ${ }^{2,3}$ \\ 'Department of Nephrology, Faro \\ Hospital, Faro, Portugal; ${ }^{2}$ Department \\ of Nephrology, Hospital São João, \\ Porto, Portugal; ${ }^{3}$ Medical School \\ and Nephrology Research and \\ Development Unit, University of \\ Porto, Porto, Portugal
}

\section{Dear editor}

Atherosclerotic cardiovascular disease (ASCVD) is the leading cause of mortality and death-censored graft loss after renal transplantation. ${ }^{1}$ Acute cardiovascular events have been reported as the principal clinical manifestations, but hypertension could be a form of ASCVD presentation, being able to promote its progression undetected. ${ }^{2}$

We describe a case of a 62-year-old African woman who presented with kidney graft dysfunction attributed to an abrupt worsening of hypertension. She had a history of hypertension since she was 21 years old. At 44 years old, she was referred to our Nephrology clinic due to uncontrolled hypertension and chronic kidney disease. Secondary causes were excluded and kidney biopsy revealed lesions compatible with hypertensive nephrosclerosis. In spite of controlled hypertension, she began hemodialysis at 56 years old. Three years later, she received an HLA (human leukocyte antigen) identical deceased donor kidney, with creatinine stabilized at $1.4 \mathrm{mg} / \mathrm{dL}$. At that time, arterial occlusive disease was ruled out. She had a unique episode of allograft dysfunction 7 months later, due to Banff grade IA acute cellular rejection and promptly reverted by rejection rescue therapy. During posttransplant period, the patient maintained asymptomatic hypertension, controlled with progressively higher doses of combined antihypertensive drugs. An annual Doppler ultrasonography (DUS) was performed as a screening modality and creatinine remained around $1.4 \mathrm{mg} / \mathrm{dL}$.

Two years after renal transplant, she was admitted in the emergency room with a blood pressure of 230/113 mmHg. At that time she was taking high doses of four antihypertensive drugs. She had no complaints, but seemed confused. Physical examination initially appeared unremarkable. Her serum creatinine increased to $2.4 \mathrm{mg} / \mathrm{dL}$, with preserved urine output. The DUS revealed significantly diminished perfusion of the grafted kidney. Consequently, a computed tomographic angiography (CTA) was performed, demonstrating a complete occlusion of the right common and internal iliac arteries, and occlusion of the right external iliac artery just above the origin of the renal transplant artery (Figure 1). Angiography confirmed the findings of the CTA, demonstrating a retrograde feeding of the renal transplant artery from the common femoral artery, and excluding relevant occlusive disease on the left iliac arteries.

Considering the occlusion extension and its calcium content, a femorofemoral bypass was performed. In the postoperative period, the DUS showed a restored perfusion of the allograft. The serum creatinine also normalized. Additionally, the blood pressure dropped notably, allowing the discharge of the patient with only two antihypertensive agents.
Correspondence: Ana Pinho Department of Nephrology, Faro Hospital, Leão Penedo, 8000-386 Faro, Portugal Tel +351917881154 Fax +35I 2295 II 653 Email ana.pinho82@gmail.com submit your manuscript | www.dovepress.com Dovepress 


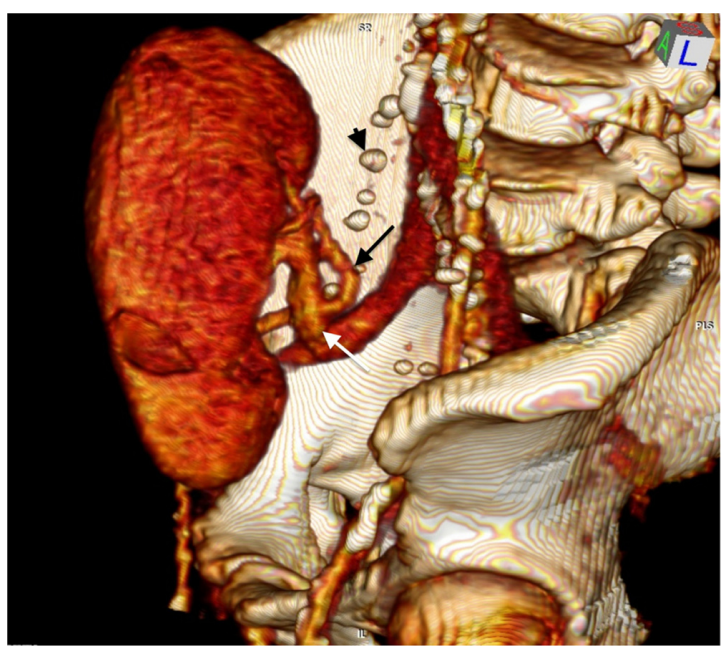

Figure I Three-dimensional CTA reconstruction.

Notes: Black arrow indicates arterial anastomosis of the allograft; white arrow indicates venous anastomosis of the allograft; arrowhead indicates calcified occlusion of the right common and external iliac arteries proximal to the allograft.

Abbreviation: CTA, computed tomographic angiography.

Hypertension after renal transplantation can result from several causes, and is sometimes difficult to clarify. ${ }^{2}$ Few case studies have described these kind of lesions, ipsilateral to a patent renal transplant artery. ${ }^{3}$ Fewer case series papers reported a pretransplant prevalence of ipsilateral iliac occlusive disease of around $1.8 \%,{ }^{4}$ and posttransplant around $1.3 \%-2.4 \%{ }^{3,5}$ In the reported case, we observed an accelerated atherosclerotic progression after renal transplantation, since no iliac occlusive disease was found at the time of renal transplantation. In the absence of significant cardiovascular symptoms, it can be difficult to raise the suspicion of ASCVD causing progressive deterioration of hypertension. Moreover, the annual screening with DUS for transplant renal artery stenosis may have contributed to ambiguity. Data suggest that this technique is highly accurate, but is highly dependent upon the experience of the operator. ${ }^{4}$ When the lesions are localized higher up and deeper, the diagnosis may be very difficult, especially when the collateral circulation feeds a patent renal allograft artery. Consequently, the present case underlines the relevance of a high clinical suspicion index for underlying causes of hypertension posttransplant and the application of more accurate vascular imaging methods such as CTA.
Certainly, the risk stratification would facilitate earlier diagnosis. In retrospect, our patient with long-lasting hypertension, an event of acute graft rejection causing important inflammation, and older age, has major risk factors for accelerated ASCVD. ${ }^{1,3}$ These risk factors are not modifiable, highlighting the relevance of an early treatment. Actually, easier and shorter lesions are usually approached endovascularly with obviously better outcomes. ${ }^{6}$ Long calcified occlusions, as in the present case, are more difficult and preferentially treated by open surgery. ${ }^{6}$ The abrupt increase and severity of hypertension was highly suggestive of a viable transplanted kidney and the prompt decision to perform a femorofemoral bypass saved both the life and the graft.

Hypertension could be the first signal for an important ASCVD. Considering the increasing number of older transplanted patients with several vascular risk factors, the prevalence of iliac occlusive disease will certainly be much higher. It is our goal to create awareness about the surveillance of hypertension, which can cause undetected renal allograft hypoperfusion due to ASCVD. There is an urgent need to develop a valid approach to assess ASCVD in a timely manner after transplantation.

\section{Disclosure}

The authors report no conflicts of interest in this communication.

\section{References}

1. Vella JP, Danovitch GD. Transplantation NephSAP. J Am Soc Nephrol. 2011;10(1):596-597.

2. Mangray M, Vella JP. Hypertension after kidney transplant. Am J Kidney Dis. 2011;57(2):331-341.

3. Voiculescu A, Schmitz M, Hollenbeck M, et al. Management of arterial stenosis affecting kidney graft perfusion: a single-centre study in 53 patients. Am J Transplant. 2005;5(7):1731-1738.

4. O'Neill WC, Baumgarten DA. Ultrasonography in renal transplantation. Am J Kidney Dis. 2002;39(4):663-678.

5. Voiculescu A, Hollenbeck M, Plum J, et al. Iliac artery stenosis proximal to a kidney transplant: Clinical findings, duplex-sonographic criteria, treatment, and outcome. Transplantation. 2003;76(2):332-339.

6. Gill R, Shapiro R, Kayler LK. Management of peripheral vascular disease compromising renal allograft placement and function: review of the literature with an illustrative case. Clin Transplant. 2011;25(3): 337-344.

\section{Publish your work in this journal}

The International Journal of Nephrology and Renovascular Disease is an international, peer-reviewed open-access journal focusing on the pathophysiology of the kidney and vascular supply. Epidemiology, screening, diagnosis, and treatment interventions are covered as well as basic science, biochemical and immunological studies. The journal welcomes

\section{Dovepress}

original research, clinical studies, reviews \& evaluations, expert opinion and commentary, case reports and extended reports. The manuscript management system is completely online and includes a very quick and fair peerreview system, which is all easy to use. Visit http://www.dovepress.com/ testimonials.php to read real quotes from published authors. 